\title{
PRODUCTION AND CHARACTERIZATION OF RHIZOBIUM MELILOTI M5N1 WATER SOLUBLE EXOPOLYSACCHARIDES USING HIGH PERFORMANCE LIQUID CHROMATOGRAPHY
}

\author{
JOSIANE COURTOIS, PATRICE PHEULPIN, ${ }^{1}$ ALAIN HEYRAUD,${ }^{2}$ \\ AND BERNARD COURTOIS ${ }^{1}$ \\ Laboratoire de Microbiologie, Université des Sciences et Techniques de Lille, \\ Flandres Artois 59655 VILLENEUVE D'ASCQ Cedex France \\ ${ }^{1}$ Laboratoire de Biotechnologie Microbienne I.U.T. Département de Biologie Appliquée, \\ Avenue des Facultés-Le Bailly 80025 AMIENS Cedex France \\ ${ }^{2}$ Laboratoire de Physico-chimie Macromoléculaire, Centre de recherches \\ sur les Macromolécules Végétales, Centre National de la Recherche Scientifique, \\ BP 68-38402 SAINT MARTIN D'HERES Cedex France
}

(Received April 16, 1990)

\begin{abstract}
High performance gel filtration chromatography with several on line detectors (refractometer, polarimeter, laser-light scattering, viscosimeter) revealed to be useful tools in the production study and characterization of exopolysaccharides from Rhizobium meliloti M5N1 strain.
\end{abstract}

Polysaccharide dosage was a limiting step in the production study of biopolymers by micro-organisms. Until now, some long technics were used and the main problem was to separate produced exopolysaccharides from residual monosaccharide in the microbial suspensions. The dried weights of ethanol precipitated polysaccharides or chemical dosages (as sulfuric phenol or orcinol) were determined from the undialyzable part of centrifuged microbial suspensions. We also counted the radioactivity of labeled isotopes containing polymeric material separated from residual labeled sugar by either paper chromatography (9) or gel permeation on Sephadex (2).

In this paper, we propose a rapid measurement of both exopolysaccharide and residual fructose by high performance exclusion chromatography with the contribution of several detectors $(4,6,8)$. This method has been used with exopolysaccharide from Rhizobium meliloti M5N1 strain cultivated on RC medium (7) with fructose as a carbon source.

* Address reprint requests to: Dr. B. Courtois, Laboratoire de Biotechnologie Microbienne I.U.T. Département de Biologie Appliquée, Avenue des Facultés-Le Bailly 80025 AMIENS Cedex France. 


\section{MATERIALS AND METHODS}

Cultivation of the organism. R. meliloti M5N1 strain nodulating Medicago sativa was used in exopolysaccharide synthesis.

Media and culture conditions were as described in a previous paper $(1,3,5)$.

During $211 \mathrm{~h}$ of incubation in RC (Rhizobium complet) medium (7) containing per liter: $\mathrm{MgSO}_{4} \cdot 7 \mathrm{H}_{2} \mathrm{O}, 0.2 \mathrm{~g} ; \mathrm{K}_{2} \mathrm{HPO}_{4}, 1.0 \mathrm{~g}$; Yeast Extract (Difco), $1.0 \mathrm{~g}$, supplemented with fructose $1 \%(\mathrm{~W} / \mathrm{V})$, samples were centrifuged at $51,520 \times g$ for $20 \mathrm{~min}$. The cell-free solution was separated from the pellet. $\mathrm{NaN}_{3}, 0.01 \mathrm{M}$, was added to the supernatant.

Characterization of exopolysaccharides by high performance liquid chromatography. The polysaccharides were characterized by gel filtration chromatography at room temperature using a modified Waters 150C apparatus with multidetection: a differential refractometer for concentration, a capillary viscosimeter for intrinsic viscosity $(\eta)$, and a low angle light scattering detector (CHROMATIX CMX 100) for molecular weight (8). Two aqueous gel filtration columns, B-804 and B-805 $\left(8 \times 500 \mathrm{~mm}\right.$ with a pore size of $5 \times 10^{5} \AA$ and $5 \times 10^{6} \AA$ respectively), from Shodex, were applied in series with $0.1 \mathrm{~N} \mathrm{NaNO}_{3}$ as eluent. The samples were filtered through a $0.22 \mu \mathrm{m}$ filter before injection. The injected volumes were in the range $100-250 \mu \mathrm{l}$.

In the production study, the liquid chromatograph was a model 6000 and an U6K injector (Waters Chromatography Division, Milford, Mass.). Gel filtration columns were Shodex B-803, B-805 and B-806 $(8 \times 500 \mathrm{~mm}$ with a pore size of $1 \times 10^{5} \AA, 5 \times 10^{6} \AA, 2.5 \times 10^{7} \AA$ respectively), in series with $0.1 \mathrm{~N} \mathrm{NaCl}$ as the mobile phase at a flow rate of $1 \mathrm{ml} \cdot \mathrm{min}^{-1}$. The injected volumes were $250 \mu \mathrm{l}$ with concentration ranging from 0.04 to $1.5 \mathrm{~g} / \mathrm{l}$ for exopolysaccharide and 1 to $10 \mathrm{~g} / \mathrm{l}$ for fructose.

The detection systems were the analytical IOTA refractive index detector (Jobin-Yvon, France) in series with a Perkin Elmer Model 241 polarimeter equipped with a $80 \mu \mathrm{l}$ microflow cell operating at $365 \mathrm{~nm}$ with 0.05 degree full scale (6).

The calibration curves (Fig. 1) were obtained using several exopolysaccharides or fructose solutions at different concentrations.

Exopolysaccharides obtained at different times of fermentation were analyzed by total acid hydrolysis and ${ }^{1} \mathrm{H} \mathrm{n}$. m. r. studies as described in a previous paper (3).

\section{RESULTS AND DISCUSSION}

The main problem in the production studies of exopolysaccharides by fermentation is to quantify separately the produced polymer and the carbon source consumed. Liquid chromatography is a powerful technic in this separation, but the difficulty is the detection, due to the great difference between the concentrations of polysaccharide and fructose and the utilization of a differential refractometer. The combination of gel filtration chromatography with an on line polarimeter and a 

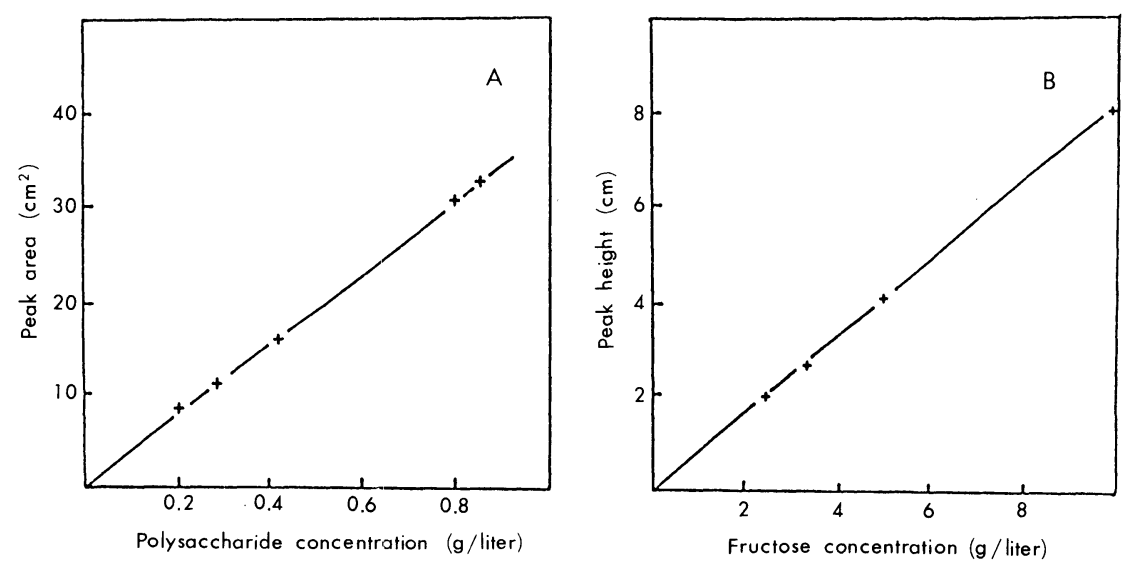

Fig. 1. HPLC calibration curves for dosage of $R$. meliloti M5N1-synthesized exopolysaccharide (A) and of fructose (B) (column: Shodex B-803, B-805 and B-806; eluent: $\mathrm{NaCl} 0.1 \mathrm{~N}$; flow rate: $1 \mathrm{ml} / \mathrm{min}$; detectors: R.I. for polysaccharide and polarimeter for fructose.

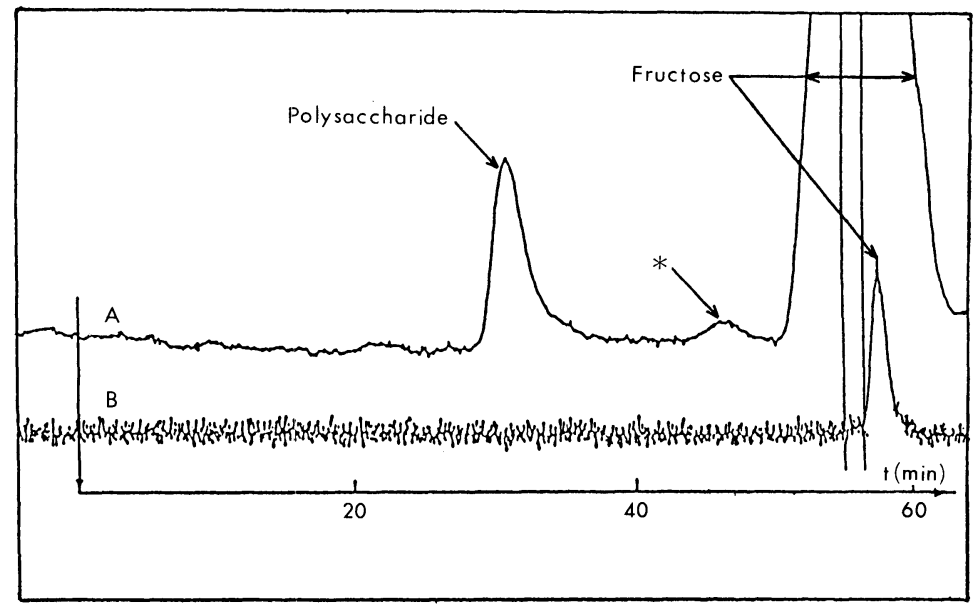

Fig. 2. Elution profiles of polysaccharide and fructose volumes for $t=52 \mathrm{~h}$. (A: R.I. detection, $6 \times 10^{-6} \mathrm{RIU} / \mathrm{F}$. B: polarimetric detection, 0.05 degree FS). ${ }^{*}$ Traces of RC medium components.

differential refractometer gives interesting results.

The polysaccharide fractionated on the column set was detected by refractometry. The fructose generally eluted at the total volume of the chromatographic system with the medium salts was analyzed with a polarimeter for specific identification (Fig. 2). Both the polysaccharides and the fructose were quantified using calibration curves (Fig. 1). Figure 3 shows the production of polysaccharide and the consumption of fructose in 19 to $211 \mathrm{~h}$ of fermentation. 


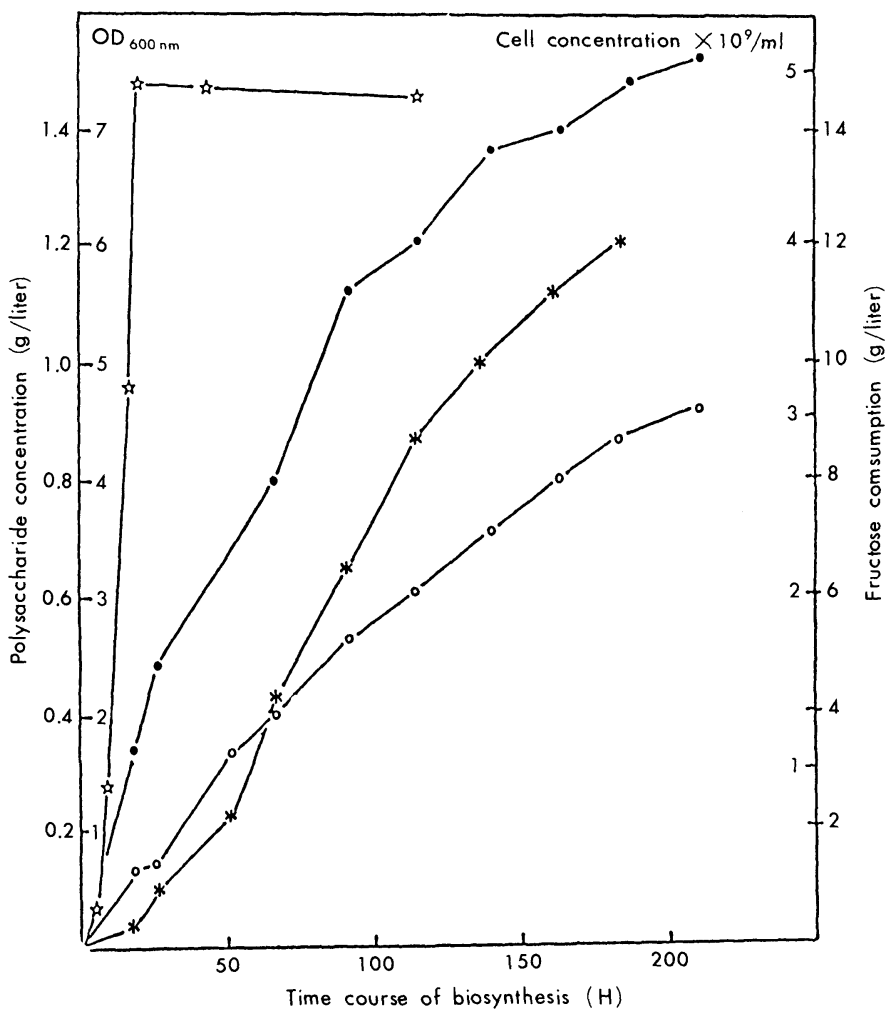

Fig. 3. Kinetic of polysaccharide biosynthesis by $R$. meliloti M5N1 strain during growth in fructose-RC medium $\left(*\right.$ : polysaccharide concentration $\mathrm{g} \cdot \mathrm{l}^{-1}, \mathrm{O}$ : fructose consumption $\mathrm{g} \cdot \mathrm{l}^{-1}$, $\bullet$ : optical density at $600 \mathrm{~nm}$ of the suspension cell, 5 : cell concentration in the cell suspension).

The described technic is a rapid and reliable method in the production study. To characterize the polysaccharides we used specific detectors in liquid chromatography and gel filtration chromatography. The combination of gel filtration chromatography with laser light-scattering detection, a differential refractometer and an on line viscosimeter allows a complete characterization with the direct determination of the molecular weight distribution without any calibration. In addition we determined the parameters $K$ and $a$ of the Mark-Houwink relation $\left([\eta]=K M^{a}\right)(8)$.

Four samples, $T_{1}=19 \mathrm{~h}, T_{2}=67 \mathrm{~h}, T_{3}=139 \mathrm{~h}$ and $T_{4}=211 \mathrm{~h}$ have been investigated. An example of chromatogram is given (Fig. 4) and the physicochemical data are listed in Table 1. The values of the molecular weight and the intrinsic viscosity are closely similar. Apparently the polysaccharide elaborated is the same at the beginning and at the end of the fermentation process. The structures were analyzed and the results agree with previous data(3). The polysaccharide is a succinoglycan and there is no difference in the substituent groups (O-succinyl, 


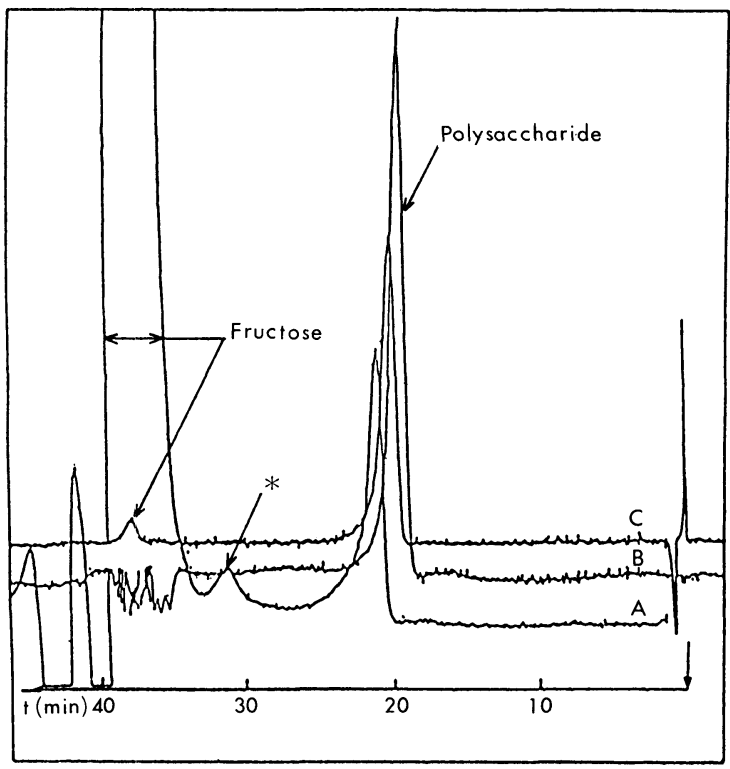

Fig. 4. Chromatogram obtained in gel filtration chromatography using multidetection to characterize the extracellular polysaccharide of $R$. meliloti $\mathrm{M} 5 \mathrm{~N} 1$ strain (A: R.I.; B: Laser light scattering; C: capillary viscosimeter). ${ }^{*}$ Traces of RC medium components.

Table 1. Physicochemical characteristics of extracellular polysaccharide biosynthesized by $R$. meliloti $\mathrm{M} 5 \mathrm{~N} 1$ strain for different fermentation times.

\begin{tabular}{cccc}
\hline $\begin{array}{c}\text { Incubation } \\
\text { time (h) }\end{array}$ & $\begin{array}{c}\text { Weight average } \\
(\mathrm{MW})\end{array}$ & $\begin{array}{c}\text { Intrinsic } \\
\text { viscosity }\end{array}$ & $\begin{array}{c}\text { Polymolecularity } \\
\text { index }(I)\end{array}$ \\
\hline$T_{1}(27)$ & $3.45 \times 10^{6}$ & 6,516 & 1.07 \\
$T_{2}(67)$ & $3.69 \times 10^{6}$ & 6,479 & 1.04 \\
$T_{3}(139)$ & $3.82 \times 10^{6}$ & 6,836 & 1.04 \\
$T_{4}(211)$ & $3.80 \times 10^{6}$ & 6,711 & 1.07 \\
\hline
\end{tabular}

$\mathrm{MW}=$ Molecular weight.

O-acetyl and pyruvic acid acetal groups) among the four samples.

Due to the progress in high performance size exclusion chromatography and the development of specific new detectors, liquid chromatography is now a powerful technic in the studies of fermentation process and characterization of products in the field of water-soluble exopolysaccharides. The combination of a refractometer and an on line polarimeter allows us to follow the synthesis of the polymer and the disappearance of the carbon source. The molecular weight and some physicochemical data are available using on line a laser light-scattering detector, a refractometer and a viscosimeter. These technics will allow kinetic studies, 
particularly to investigate biosynthesis by studying the modification in polysaccharide production, in physicochemical variations in characteristics with different culture conditions, or in the modifications of polysaccharides produced by different mutated strains.

We thank Ph. Colin-Morel and E. Fouissac for assistance in the experimental work.

\section{REFERENCES}

I) Courtois, B., Hornez, J. P., and Derieux, J. C., Effet de la synthese d'acide 2 céto-gluconique par une souche de Rhizobium meliloti. Can. J. Microbiol., 25, 1191-1196 (1979).

2) Courtois, B., Hornez, J. P., Tailliez, R., Courtois, J., and Derieux, J. C., Méthode rapide de dosage des exopolysaccharides solubles produits par Rhizobium meliloti. C. R. Acad. Sci. Paris, 294, III, 95-98 (1982).

3) Courtois, B., Courtois, J., Heyraud, A., and Rinaudo, M., Effect of biosynthesis conditions on chemical composition of water soluble polysaccharides of fast growing Rhizobia. J. Gen. Appl. Microbiol., 32, 527-534 (1986).

4) Heyraud, A. and Salemis, P., Liquid chromatography in the methylation analysis of carbohydrates and the use of combined refractometric-polarimetric detection. Carbohydr. Res., 107, 123-129 (1982).

5) Heyraud, A., Rinaudo, M., and Courtois, B., Comparative studies of extracellular polysaccharide elaborated by Rhizobium meliloti strain M5N1 in defined medium and in non growing cell suspensions. Int. J. Biol. Macromol., 8, 85-89 (1986).

6) Heyraud, A. and Rinaudo, M., Advantages of an optical activity detector in size exclusion chromatography of polysaccharides. J. Appl. Polymer Sci. (in press).

7) Laird, D. J., Bacteriophage and the root nodule bacteria. Arch. Microbiol., 3, 159-193 (1932).

8) Tinland, B., Mazet, J., and Rinaudo, M., Characterization of water-soluble polymers by multidetection size-exclusion chromatography. Macromol. Chem. Rapid Commun., 9, 69-73 (1988).

9) Williams, A. G. and Winpenny, W. T., Extracellular polysaccharide biosynthesis by Pseudomonas NCIB IR64. Studies on precursor forming enzymes and factors affecting exopolysaccharide production by washed suspensions. J. Gen. Microbiol., 116, 133-141 (1980). 